\title{
Epithelium-on corneal cross-linking treatment of progressive keratoconus: a prospective, consecutive study
}

This article was published in the following Dove Press journal:

Clinical Ophthalmology

29 April 2014

Number of times this article has been viewed

\author{
Hany A Khairy \\ Hatem M Marey \\ Amin Faisal Ellakwa \\ Ophthalmology Department, Menoufia \\ University Hospitals, Menofia, Egypt
}

Purpose: To evaluate the outcome of collagen cross-linking (CXL) without corneal epithelial debridement in patients treated for progressive keratoconus for whom the standard epitheliumoff treatment cannot be applied, as their central corneal thickness (CCT) is less than $400 \mu \mathrm{m}$.

Patients and methods: This was a prospective, uncontrolled, interventional study involving 32 eyes of 30 patients with progressive keratoconus and CCT of less than $400 \mu \mathrm{m}$. All patients received CXL treatment with application of riboflavin and exposure to ultraviolet light $\mathrm{A}$ for 30 minutes without corneal epithelial debridement. Patients were followed up to 12 months postoperatively. The main outcomes were changes in maximum-K reading, manifest refractive spherical equivalent, CCT, and best-corrected visual acuity (logarithm of minimum angle of resolution). Patients were also asked to report any pain or discomfort during the procedure. Results: At the end of the 12-month follow-up, CCT showed no significant change: from $392 \pm 5.17 \mu \mathrm{m}$ preoperatively to $390 \pm 4.45 \mu \mathrm{m}(P=0.102)$. Maximum-K reading decreased significantly, from $49.19 \pm 2.30 \mathrm{D}$ preoperatively to $46.96 \pm 6.03 \mathrm{D}$ postoperatively $(P<0.05)$. The mean manifest spherical equivalent showed no significant change: from $4.04 \pm 1.51 \mathrm{D}$ preoperatively to $4.17 \pm 1.63 \mathrm{D}$ postoperatively $(P=0.110)$. Mean best-corrected visual acuity showed no significant change: from $0.29 \pm 0.12$ preoperatively to $0.31 \pm 0.11$ postoperatively $(P=0.110)$.

Conclusion: Epithelium-on CXL exhibits potential as a method for treating patients with progressive keratoconus and CCT of less than $400 \mu \mathrm{m}$, in which the standard epithelium-off CXL cannot be applied. Over 12 months of follow-up, the epithelium-on CXL was safe and effective, with results comparable to that achieved with the epithelium-off technique in thicker corneas, and reduced rates of operative and postoperative discomfort.

Keywords: keratoconus, cross-linking, refractive surgery, epithelium

\section{Introduction}

Treatment for progressive keratoconus involves interventions that are done for tectonic, optical, or refractive purposes. Collagen cross-linking (CXL) is the latest treatment in the series, and may offer some promise in that it is the only intervention that can potentially slow down the progression of the disease. ${ }^{1}$

CXL works by increasing the collagen cross-links and thereby strengthening the human cornea by up to $328.9 \%$. A beneficial side effect of CXL in many patients is flattening and regularization of the conic corneal shape, which in turn can cause a reduction of myopia and astigmatism. ${ }^{2-6}$

Since Wollensak et $\mathrm{al}^{2}$ published their first report in 2003, the technique has been adopted by many investigators, with favorable outcomes. In a study involving 44 patients followed up for 3 years, Mazzotta et $\mathrm{al}^{7}$ reported epithelial regeneration in
Correspondence: Amin Faisal Ellakwa University Hospital, Menofia 325I I, Egypt Tel +20100528 8543

Email ellakwa@yahoo.com 
4 days, with no damage observed to the limbus. The epithelium maintained its healthy stratification. The regeneration of subepithelial plexus started in the first month and was completed by the sixth month. The corneal stroma started repopulation by the second month and was completed by the sixth month. ${ }^{7}$

In their prospective, nonrandomized study of 102 patients for 12 months who had CXL for keratoconus, Grewal et $\mathrm{al}^{8}$ reported stable best-corrected visual acuity, spherical equivalent, anterior and posterior corneal curvature, and corneal elevation at the end of the follow-up period.

Although the standard technique involves removal of the epithelium in a zone of 7-9 $\mathrm{mm}$, a recent study on rabbit eyes, where riboflavin-ultraviolet cross-linking was carried out without epithelial removal, found a lower penetration depth of $200 \mu \mathrm{m}$, which is an advantage over the standard method in reducing corneal cytotoxic damage. Epitheliumon technique has also reduced the biomechanical effect by approximately $20 \%$, probably because of the restricted and inhomogeneous stromal distribution of riboflavin; therefore, it is recommended primarily for cases with central corneal thickness (CCT) of less than $400 \mu \mathrm{m}$, in which CXL cannot be used without serious risk to the endothelium. ${ }^{9}$

In this series, we studied the outcome of CXL with epithelium-on in patients diagnosed with keratoconus with CCT of less than $400 \mu \mathrm{m}$, which did not allow them to have the standard epithelium-off CXL treatment.

\section{Patients and methods}

This was a prospective, uncontrolled, interventional study involving 32 eyes of 30 patients. Patients were recruited from the Eye Outpatient Department at Menoufia University Hospital, Egypt between January 2012 and October 2012.

Eligible patients were adults aged above 18 years. They had been diagnosed clinically with keratoconus, and had clinical evidence of progression, best-corrected visual acuity of 0.8 (logarithm of minimum angle of resolution [LogMAR]) or better in each eye, CCT measuring $<400 \mu \mathrm{m}$, and open anterior chamber angle on gonioscopy, and were willing to attend the eye clinic at the times required by the study design.

Evidence of progressive keratoconus included increase in keratometry readings (mean $\mathrm{K}$ or max $\mathrm{K}$ ) of greater than $1.00 \mathrm{D}$, increase in mean spherical refractive equivalent by $0.50 \mathrm{D}$, increase in astigmatism by $1.00 \mathrm{D}$, the need for a new contact lens fitting in the space of 2 years, or a decrease in patient's visual acuity over the previous 2 years by one or more lines on the LogMAR chart.
Patients were excluded from the study when they had corneal opacities due to other corneal pathologies, had a history of chronic eye diseases, had a previous ocular laser or surgical treatment, or had a history of systemic medical condition or medications that could affect the cornea.

Data collected from patients included age, past ocular and medical history, medications, allergies, and family history of ocular diseases. Patients had baseline assessment at their preoperative visit, including LogMAR, intraocular pressure measurement with applanation tonometry (Goldmann, Haag-Streit AG, Koeniz, Switzerland), gonioscopy with three-mirror Gonio contact lens (Ocular Instruments, Bellevue, WA, USA), dilated fundus examination with $+78 \mathrm{D}$ Volk lens (Volk Optical, Mentor, OH, USA) optic disk stereo photography, and corneal topography by Pentacam ${ }^{\circledR}$ (Oculus, Wetzlar, Germany).

The study protocol was approved by the ethical committee of Menoufia Medical School. The study protocol was explained to the patients, and all patients provided written informed consent.

\section{Surgical procedure}

One experienced surgeon (HM) performed all surgeries using topical anesthesia. Patients were prepared and draped. After topical anesthesia (benoxinate hydrochloride $0.4 \%$ ), the corneal surface was then treated by the application of riboflavin (hypotonic riboflavin $0.1 \%$, Mediocross $\mathrm{TE}^{\circledR}$; Peschke Meditrade GmbH, Hünenberg, Switzerland), for 30 minutes, starting 5 minutes before the start of irradiation. Ultraviolet A radiation of $365 \mathrm{~nm}$ wavelength (CCL-365 Vario; Peschke Meditrade $\mathrm{GmbH}$ ) and an irradiance of $3 \mathrm{~mW} / \mathrm{cm}^{2}$ (spot size $7 \mathrm{~mm}$ ) at a distance of $45 \mathrm{~mm}$ from the cornea was applied for a period of 30 minutes, delivering a dose of $5.4 \mathrm{~J} / \mathrm{cm}^{2}$. Antibiotic drops were instilled as prophylaxis, and an eye bandage was left for 24 hours. Patients were asked to use dexamethasone $0.1 \%$ eyedrops, and chloramphenicol $0.5 \%$ eyedrops four times daily for 1 week postoperatively.

The main outcomes for comparison were changes in maximum- $\mathrm{K}$ reading, manifest refractive spherical equivalent, CCT, and best-corrected visual acuity. Patients were also asked to report any pain or discomfort during the procedure.

Patients were followed up clinically on the first day, and at 1 week, 1 month, and 12 months postoperatively, but the measurements were done only at the 12-month visit. Obtained data are presented as means \pm standard deviation. Results 
were analyzed using the Mann-Whitney-Wilcoxon test. Statistical analysis was conducted using SPSS version 15 for Windows (SPSS, Chicago, IL, USA) statistical package. $P$-values $<0.05$ were considered statistically significant.

\section{Results}

The study included 32 eyes of 30 patients: 18 males and 12 females, with a mean age of $22.0 \pm 2.99$ years. All patients had evidence of progressive keratoconus. Twelve patients had other associated medical comorbidities, eleven had atopy, and one had heart problems.

All surgeries passed uneventfully, without intraoperative complications. At the end of the 12-month follow-up, CCT showed no significant change: from $392 \pm 5.17 \mu \mathrm{m}$ preoperatively to $390 \pm 4.45 \mu \mathrm{m}$ postoperatively $(P=0.102)$. The maximum-K reading decreased significantly from $49.19 \pm 2.30 \mathrm{D}$ preoperatively to $46.96 \pm 6.03 \mathrm{D}$ postoperatively $(P<0.05)$. Mean manifest spherical equivalent showed no significant change: from $4.04 \pm 1.51 \mathrm{D}$ preoperatively to $4.17 \pm 1.63 \mathrm{D}$ postoperatively $(P=0.110)$. Mean best-corrected visual acuity (LogMAR) showed no significant change: from $0.29 \pm 0.12$ preoperatively to $0.31 \pm 0.11$ postoperatively $(P=0.110)$ (Table 1). Patients did not report any significant subjective pain or discomfort during the procedure or postoperatively, but reported visual blurriness in the first week postoperatively.

\section{Discussion}

CXL treatment using riboflavin and ultraviolet light has been developed to slow the progression of keratoconus and to defer the need for corneal transplant. In their long-term retrospective trial, Raiskup-Wolf et $\mathrm{al}^{6}$ studied the results of CXL in 241 eyes of patients with progressive keratoconus.

Table I Mean outcome values preoperatively and postoperatively

\begin{tabular}{|c|c|c|c|}
\hline \multirow[t]{2}{*}{ Variable } & \multicolumn{2}{|c|}{$\begin{array}{l}\text { Mean } \pm \text { SD, (confidence } \\
\text { interval } 95 \% \text { ) }\end{array}$} & \multirow[t]{2}{*}{ Significance } \\
\hline & Preoperative & Postoperative & \\
\hline CCT & $\begin{array}{l}392 \pm 5.17 \mu \mathrm{m} \\
(390.21-393.79)\end{array}$ & $\begin{array}{l}390 \pm 4.45 \mu \mathrm{m} \\
(388.46-391.54)\end{array}$ & $P=0.102$ \\
\hline Maximum-K & $\begin{array}{l}49.19 \pm 2.30 \mathrm{D} \\
(48.39-49.99)\end{array}$ & $\begin{array}{l}46.96 \pm 6.03 \mathrm{D} \\
(44.87-49.05)\end{array}$ & $P<0.05^{*}$ \\
\hline $\begin{array}{l}\text { The mean } \\
\text { manifest spherical } \\
\text { equivalent }\end{array}$ & $\begin{array}{l}4.04 \pm I .5 I D \\
(3.52-4.56)\end{array}$ & $\begin{array}{l}4.17 \pm I .63 \mathrm{D} \\
(3.6 I-4.74)\end{array}$ & $P=0.110$ \\
\hline $\begin{array}{l}\text { Mean best- } \\
\text { corrected visual } \\
\text { acuity (logMAR) }\end{array}$ & $\begin{array}{l}0.29 \pm 0.12 \\
(0.25-0.33)\end{array}$ & $\begin{array}{l}0.31 \pm 0.11 \\
(0.27-0.35)\end{array}$ & $P=0.110$ \\
\hline
\end{tabular}

Note: *Significant.

Abbreviations: SD, standard deviation; CCT, central corneal thickness; logMAR, logarithm of minimum angle of resolution; Maximum $\mathrm{K}$, mean maximum keratometry reading.
They reported that the steepening of the cornea decreased significantly by $2.68 \mathrm{D}$ in the first year, $2.21 \mathrm{D}$ in the second year, and 4.84 D in the third year. Best-corrected visual acuity improved significantly (one or more lines) in $53 \%$ of 142 eyes in the first year, $57 \%$ of 66 eyes in the second year, and $58 \%$ of 33 eyes in the third year or remained stable (no lines lost) in $20 \%, 24 \%$, and $29 \%$, respectively. ${ }^{6}$

Hashemi et a ${ }^{10}$ reported the longest study, with a 5 -year follow-up period. The study was conducted on 40 eyes of 32 patients with progressive keratoconus. Mean K, max K, uncorrected visual acuity, and astigmatism showed no change during the 5 years. After the first year, best-corrected visual acuity, manifest refraction spherical equivalent, and CCT showed no change and stabilized, whereas elevation readings continued to decrease up to 5 years after CXL. ${ }^{10}$

There are variations in the technique used by many investigators, but most of them removed the corneal endothelium 7-9 $\mathrm{mm}$ centrally, then treated the surface by applying riboflavin $0.1 \%$ solution for 30 minutes, starting 5 minutes before the irradiation. ${ }^{1}$ The standard CXL treatment requires epithelial debridement, which results in pain and discomfort to the patient and delayed visual rehabilitation. Leaving the epithelium untouched, however, may significantly impair the efficacy of the procedure, and increases the risk of ultraviolet damage to the eye. ${ }^{911}$

Mastropasqua et al ${ }^{12}$ studied the difference in riboflavin concentration in the different layers of cadaver corneal stroma after three CXL imbibition techniques (standard epithelium-off, epithelium-on, and iontophoresis-assisted administration) of riboflavin $0.1 \%$. They concluded that CXL transepithelial iontophoresis imbibition yielded greater and deeper riboflavin saturation with respect to conventional epithelium-on, but did not reach the concentration obtained with standard epithelium-off. ${ }^{12}$

In another trial by Bikbova and Bikbov, ${ }^{13}$ transepithelial impregnation with riboflavin iontophoresis was used in a series of 22 eyes with progressive keratoconus. The results of the treatment showed a decrease in the average keratometry level from $46.47 \pm 1.03 \mathrm{D}$ to $44.12 \pm 1.12 \mathrm{D} 1$ year after the procedure. Corneal astigmatism decreased from $3.44 \pm 0.48 \mathrm{D}$ to $2.95 \pm 0.23 \mathrm{D}$. Uncorrected distance visual acuity improved from $0.61 \pm 0.44$ to $0.48 \pm 0.41$ (LogMAR). Preoperative and postoperative endothelial cell density remained unchanged at $2765 \pm 21.15 \mathrm{cells} / \mathrm{mm}^{2}$. The results confirmed the effectiveness of this method in reducing the duration of the procedure and being more comfortable for the patients. ${ }^{13}$ 
Many experimental and clinical investigations have shown that intact epithelium does not block the effect of ultraviolet $\mathrm{A}$ light, but decreases the effectiveness of the CXL treatment by impairing the adequate stromal diffusion of riboflavin. ${ }^{14-19}$ In this study, the analysis involved 32 eyes of 30 patients who have been followed up for 12 months. There was no loss to follow-up at any point during the 12 months. The maximum-K reading decreased significantly from $49.19 \pm 2.3$ preoperatively to $46.96 \pm 6.03$ postoperatively $(P<0.05)$. Best-corrected visual acuity did not change significantly: from $0.29 \pm 0.12$ preoperatively to $0.31 \pm 0.11$ postoperatively. Neither manifest refractive spherical equivalent nor CCT showed any statistically significant difference postoperatively compared to their preoperative values. Patients did not record any significant pain postoperatively, but most of them recorded visual blurriness in the first week.

In their study on rabbit eyes, Wollensak et $\mathrm{al}^{9}$ found that the cytotoxic damage of CXL without epithelial removal was restricted to $200 \mu \mathrm{m}$ stromal depth, and they concluded that this could open the door to use CXL for cases with CCT less than $400 \mu \mathrm{m}$, in which standard epithelial-off CXL cannot be used without serious risks to the endothelium. ${ }^{8}$

In a prospective, consecutive, single-masked, paired eye study on 51 patients by Leccisotti et al, ${ }^{17}$ the clinical effects of transepithelial CXL on keratoconic eyes with CCT $>400 \mu \mathrm{m}$ pre-treated with gentamicin, benzalkonium chloride, and ethylenediaminetetraacetic acid to enhance the epithelial permeability of riboflavin, were evaluated. They showed significant improvement in mean corrected distance visual acuity, mean spherical equivalent refraction, and mean average simulated keratometry. The favorable effect of their transepithelial approach appeared to be less pronounced than the standard CXL with de-epithelialization. ${ }^{17}$

To the best of our knowledge, this is the first report of epithelium-on CXL in patients with corneal thickness of less than $400 \mu \mathrm{m}$. However, there were several limitations of this study. First, the number of patients recruited was small, due to the strict inclusion criteria. The second limitation was the short-term follow-up; however, most similar studies were designed with short-term follow-up. The third limitation of the study was the lack of study of the effect of the treatment on the corneal endothelium (by specular microscopy). More prospective, double-masked, randomized trials are needed to demonstrate whether the same results could be applied to patients with CCT more than $400 \mu \mathrm{m}$.

To conclude, epithelium-on CXL exhibits potential as a method for treating patients with progressive keratoconus and CCT of less than $400 \mu \mathrm{m}$, for whom the standard epithelium-off CXL cannot be applied. Over 12 months of follow-up, the epithelium-on CXL was safe and effective, with results comparable to that achieved with the epitheliumoff technique in thicker cornea, and with a reduced rate of operative and postoperative discomfort.

\section{Disclosure}

The authors report no conflicts of interest in this work.

\section{References}

1. Ashwin PT, Mcdonnel PJ. Collagen cross-linkage: a comprehensive review and directions for future research. Br J Ophthalmol. 2010;94: 965-970.

2. Wollensak G, Spoerl E, Seiler T. Stress-strain measurements of human and porcine corneas after riboflavin-ultraviolet-A-induced cross-linking. J Cataract Refract Surg. 2003;29:1780-1785.

3. Wollensak G, Spoerl E, Seiler T. Riboflavin/ultraviolet-A-induced collagen crosslinking for the treatment of keratoconus. $\mathrm{Am} \mathrm{J}$ Ophthalmol. 2003;135:620-627.

4. Vinciguerra P, Albè E, Trazza S, et al. Refractive, topographic, tomographic, and aberrometric analysis of keratoconic eyes undergoing corneal cross-linking. Ophthalmology. 2009;116:369-378.

5. Hersh PS, Greenstein SA, Fry KL. Corneal collagen crosslinking for keratoconus and corneal ectasia: one-year results. $J$ Cataract Refract Surg. 2011;37:149-160.

6. Raiskup-Wolf F, Hoyer A, Spoerl E, Pillunat LE. Collagen crosslinking with riboflavin and ultraviolet-A light in keratoconus: long-term results. $J$ Cataract Refract Surg. 2008;34:796-801.

7. Mazzotta C, Balestrazzi A, Traversi C, et al. Treatment of progressive keratoconus by riboflavin-UVA-induced crosslinking of corneal collagen: ultrastructural analysis by Heidelberg retinal tomograph II in vivo confocal microscopy in humans. Cornea. 2007;26:390-397.

8. Grewal DS, Brar GS, Jain R, Sood V, Singla M, Grewal SP. Corneal collagen crosslinking using riboflavin and ultraviolet-A light for keratoconus: one-year analysis using Scheimpflug imaging. J Cataract Refract Surg. 2009;35:425-432.

9. Wollensak G, Iomdina E. Biomechanical and histological changes after corneal crosslinking with and without epithelial debridement. $J$ Cataract Refract Surg. 2009;35:540-546.

10. Hashemi H, Seyedian MA, Miraftab M, Fotouhi A, Asgari S. Corneal collagen cross-linking with riboflavin and ultraviolet an irradiation for keratoconus: long-term results. Ophthalmology. 2013;120: 1515-1520.

11. Malhotra C, Shetty R, Kumar RS, Veluri H, Nagaraj H, Shetty KB. Effect of complete epithelial debridement before riboflavinultraviolet-A corneal cross-linking therapy. J Cataract Refract Surg. 2008;34:657-661.

12. Mastropasqua L, Nubile M, Calienno R, et al. Corneal cross-linking: intrastromal riboflavin concentration in iontophoresis-assisted imbibition versus traditional and transepithelial techniques. Am J Ophthalmol. Epub December 6, 2013.

13. Bikbova G, Bikbov M. Transepithelial corneal collagen cross-linking by iontophoresis of riboflavin. Acta Ophthalmol. 2014;92:e30-e34.

14. Bottós KM, Schor P, Dreyfuss JL, Nader HB, Chamon W. Effect of corneal epithelium on ultraviolet-A and riboflavin absorption. Arq Bras Oftalmol. 2011;74:348-351.

15. Bottós KM, Dreyfuss JL, Regatieri CV, et al. Immunofluorescence confocal microscopy of porcine corneas following collagen crosslinking treatment with riboflavin and ultraviolet A. J Refract Surg. 2008;24:715-719.

16. Samaras K, O'Brart DP, Doutch J, Hayes S, Marshall J, Meek KM. Effect of epithelial retention and removal on riboflavin absorption in porcine corneas. J Refract Surg. 2009;25:771-775. 
17. Leccisotti A, Islam T. Transepithelial corneal collagen cross-linking in keratoconus. J Refract Surg. 2010;26:942-948.

18. Baiocchi S, Mazzotta C, Cerretani D, Caporossi T, Caporossi A. Corneal crosslinking: riboflavin concentration in corneal stroma exposed with and without epithelium. J Cataract Refract Surg. 2009;35:893-899.
19. Wollensak G, Aurich H, Wirbelauer C, Sel S. Significance of the riboflavin film in corneal collagen crosslinking. J Cataract Refract Surg. 2010;36:114-120.
Clinical Ophthalmology

\section{Publish your work in this journal}

Clinical Ophthalmology is an international, peer-reviewed journal covering all subspecialties within ophthalmology. Key topics include: Optometry; Visual science; Pharmacology and drug therapy in eye diseases; Basic Sciences; Primary and Secondary eye care; Patient Safety and Quality of Care Improvements. This journal is indexed on

Submit your manuscript here: http://www.dovepress.com/clinical-ophthalmology-journal

\section{Dovepress}

PubMed Central and CAS, and is the official journal of The Society of Clinical Ophthalmology (SCO). The manuscript management system is completely online and includes a very quick and fair peer-review system, which is all easy to use. Visit http://www.dovepress.com/ testimonials.php to read real quotes from published authors. 